\title{
Deliberating as a Public Representative or as a Potential User? Two Complementary Perspectives that Should Inform Health Innovation Policy
}

\author{
Participer aux délibérations en tant que représentant \\ de la population ou en tant qu'usager potentiel? \\ Deux points de vue qui devraient éclairer les politiques \\ d'innovation en santé
}

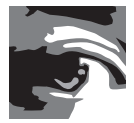 \\ PASCALE LEHOUX, PHD \\ Full Professor, Department of Health Management, Evaluation and Policy, University of Montreal \\ Institute of Public Health Research of University of Montreal (IRSPUM) \\ Montreal, QC \\ SÉBASTIEN PROULX, PHD \\ Assistant Professor, Department of Design, The Ohio State University \\ Columbus, Ohio
}

\begin{abstract}
While public involvement in health policy is gaining traction around the world, deciding whether practitioners of public involvement should encourage participants to deliberate from a personal or a collective perspective remains an object of contention. Drawing on an empirical study, the aim of this article is to generate methodological insights into these two perspectives. Our qualitative analyses illustrate how members of the public contributed differently to deliberations about the value of health innovations by alternatively sharing views as public representatives and as potential users. When engaging as public representatives, participants raised important collective concerns, and, when engaging as potential users, participants brought concrete details and contextual nuances to the group exchanges. Because these perspectives entail different yet mutually challenging ways of appraising health innovations, public engagement practitioners should foster both personal and collective perspectives.
\end{abstract}




\section{Résumé}

La participation du public gagne du terrain dans les politiques de santé partout au monde, mais il y a débat à savoir si ceux qui mettent en pratique une telle participation devraient encourager les participants à délibérer d'un point de vue personnel ou plutôt collectif. L'objectif de cet article, fondé sur une étude empirique, est de proposer des éléments de méthodologie pour ces deux points de vue. Notre analyse qualitative illustre comment les représentants de la population alternent - au cours de leurs contributions aux délibérations portant sur l'évaluation des innovations en santé - entre un rôle de représentant du public et un rôle d'usager potentiel. Quand ils adoptent le point de vue du représentant de la population, les participants font valoir d'importantes préoccupations d'ordre collectif, alors qu'ils apportent des détails concrets et des nuances contextuelles aux échanges du groupe quand ils adoptent le rôle d'usager potentiel. Puisque ces points de vue entraînent des façons différentes - quoique réciproquement enrichissantes - d'évaluer les innovations en santé, les responsables de la participation du public devraient favoriser tant le point de vue personnel que le point de vue collectif.

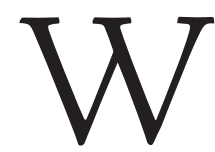

ith the Aim of INFORMING Difficult policy DeCisions, PUbliC involvement in health policy and Health Technology Assessment (HTA) (Bombard et al. 2011; Degeling et al. 2015; Facey et al. 2010; Gagnon et al. 2011) is gaining traction. As Burgess (2014: 48) puts it, public engagement "emphasizes inclusiveness so that a range of social perspectives are included beyond that of established stakeholders." Inspired by deliberative democracy theory (Gutmann and Thompson 2009), public engagement mechanisms may rely on face-to-face group discussions and online platforms that support interactions between participants. In such mechanisms, both patients and members of the public are invited to ponder the complex social and ethical issues that are raised by existing and new health technologies, thereby complementing more traditional expert-based assessment approaches (Gagnon et al. 2011, 2016; Wortley et al. 2016, 2017).

However, the multifaceted nature of lay opinions poses significant methodological challenges to practitioners of public involvement (Degeling et al. 2015; Wortley et al. 2016). One key object of contention is deciding whether participants should be contributing on the basis of their own personal perspective (i.e., as patients or users of health services) or whether they should be encouraged to talk on behalf of the broader collective (i.e., as citizens or public representatives; Delgado et al. 2010; King et al. 1998). While deliberative democracy emphasizes a form of exchange that values reasoned dialogue between various parties, defining what well-argued exchanges are remains challenging. Richard-Ferroudji (2012) and Charles (2012) observed that personal and collective concerns may receive unequal treatment by practitioners of public involvement. Warning against poorly designed public involvement mechanisms, Young (2001) underscored that participants do not engage similarly in a deliberative process 
because they may not care about the same issues and may not express these issues in a similar way. For Degeling and colleagues (2015: 119), when participants are not given a clearly defined role in a deliberative setting, it "only leads to a shallow articulation of public participation in policymaking processes." Yet, should a collective perspective be considered more meaningful than a personal one?

The aim of this article is to provide methodological insights into this question by drawing on an empirical research in which we asked members of the public to ponder both personal and collective issues when deliberating about the desirability of three prospective health technologies. Following Boenink and colleagues (2010), we developed a scenario-based method to illustrate the context in which these fictional technologies would be used in a notso-distant future (2030-2040). Four deliberative workshops followed by an online forum were organized in Quebec, Canada, and a total of 57 participants of different age groups were recruited.

While we analysed what issues participants shared regarding the value of these technologies in other publications, this current paper focuses on how they shared their views and contributed to group discussions. Our qualitative findings illustrate how participants raised collective concerns when engaging as public representatives and how they added concrete details and contextual nuances to the deliberations when engaging as potential users. Our analyses suggest that the two perspectives are necessary and complementary.

\section{Methods}

Our prospective deliberative study was designed to explore how the public perceives the value of three fictional innovations: a "smart" sweater to support cognitive enhancement in teenagers, a cardiac implant for genetically at-risk adults and an assistive robot for the elderly. We created short videos (three minutes) to explain how these technologies would work and short story-like dilemmas ( 500 words) to illustrate the prospective contexts in which they would be used in the period from 2030 to 2040. The videos were discussed in four face-to-face workshops (8-10 participants, 3.5 hours each), and the dilemmas were debated through an asynchronous online forum with additional participants (the protocol is described in greater detail here: Lehoux et al. 2014).

The study sample was constituted in accordance with qualitative research principles in which the primary intent is to generate rich and diversified data, targeting more specifically young adults (18-25 years), adults (30-55 years) and older adults ( $>60$ years). We fostered the participation of individuals from all walks of life but excluded individuals who worked in healthcare. All participants provided their consent and were attributed a pseudonym at the outset of the study. The University of Montreal's Research Ethics Board approved the study.

The workshops and forum were facilitated by a professional moderator, while an observer from the research team recorded field notes. The video describing the first 
technology was shown, and then each participant was asked to share two to three desirable and two to three undesirable features with the group. Group interactions were then prompted by asking "How should this technology be improved?" This structure, which fosters an equal opportunity to speak, as well as deliberations among participants, was repeated with the second and third technology in each workshop. The online forum started after the last workshop and was hosted on a login/password-secured blog platform (WordPress ${ }^{\circ}$ ). Participants were invited to read the scenarios and respond to questions to start the online deliberations (available in French upon request).

The workshop discussions were audio-recorded and transcribed verbatim. The content of the online forum (355 comments) was downloaded into an Excel spreadsheet. Using the web-based qualitative analysis software Dedoose ${ }^{\natural}$, we applied an iterative thematic analysis strategy (Hansen 2006). This web-based platform enabled both authors to code the whole data set, starting with pre-defined categories (e.g., nature of the judgment made: favourable or unfavourable; kinds of issue raised: social, ethical, ease of use, discomfort) and gradually identifying emerging categories. The field notes provided insights into the "serious playfulness" and respect that characterized the deliberations.

Our preliminary analyses indicated that participants easily adopted a public representative and a potential user perspective. The former perspective articulates what theorists of deliberative democracy are typically looking for, that is, a collective viewpoint, whereas the latter illustrates a personal viewpoint, which is not always seen as relevant to policy making (Young 1996). Yet, because both perspectives enabled participants to share their understanding of a broad set of social and ethical issues, we decided to further examine what these perspectives entailed. Our analyses gained more depth when we fleshed out these perspectives with the help of Thévenot's "modes of engagement," which can account for the way individuals deepen and transform their appraisal of a given situation by mobilizing various cognitive and experiential resources (Blokker and Brighenti 2011; Thévenot 2007). We carefully examined how certain values, ideas and experiences were shared and considered by participants when they engaged as a public representative and a potential user. Our findings are structured around these two perspectives, showing how group deliberations could "switch" from one perspective to another and how each of these perspectives supported different kinds of judgment.

\section{Results}

A total of 38 individuals participated in the workshops and were invited to join 25 additional participants on the forum; 32 accepted, and hence, a total of 57 individuals contributed to the forum. Using data gathered through our end-of-study survey (response rate: 81\%), Table 1 summarizes participant characteristics. 
TABLE 1. Characteristics of the participants

\begin{tabular}{|c|c|c|}
\hline & $n$ & $\%$ \\
\hline \multicolumn{3}{|l|}{ Age } \\
\hline |8-29 & 9 & 20 \\
\hline 30-39 & 6 & 13 \\
\hline 40-49 & 3 & 7 \\
\hline 50-59 & 7 & 15 \\
\hline $60-69$ & 17 & 37 \\
\hline$>70$ & 4 & 8 \\
\hline \multicolumn{3}{|l|}{ Gender } \\
\hline Women & 33 & 72 \\
\hline Men & 13 & 28 \\
\hline \multicolumn{3}{|l|}{ Education } \\
\hline High school & 4 & 9 \\
\hline Collegial & 5 & II \\
\hline University & 37 & 80 \\
\hline \multicolumn{3}{|l|}{ Household income } \\
\hline$<\mathrm{CDN} \$ 20,000$ & 4 & 9 \\
\hline$\$ 20,000-\$ 39,999$ & 9 & 19 \\
\hline$\$ 40,000-\$ 59,999$ & 17 & 37 \\
\hline$>\$ 60,000$ & 16 & 35 \\
\hline
\end{tabular}

Note: A total of 46 participants completed the demographic survey.

Our findings are structured around the two modes of engagement described earlier, which we argue support different yet mutually challenging appraisals of health technologies. As public representatives, participants raised public policy concerns such as the proper handling of data privacy. By contrast, when adopting the perspective of a potential user, participants' judgments centred on concrete details that clarified their willingness or reluctance to use the technology (e.g., fit with one's daily routine, value of certain functionalities, etc.). But in both cases, the deliberations moved forward productively: Personal preferences and insights were (re)located within a broader social and political context, and vice versa.

\section{Engaging as a public representative}

When engaging as public representatives, participants addressed or disputed the social values underlying the fictional technologies. For instance, in one of the workshops, Jeanne (pseudonym) brought forward a putative collective gain that emphasized the social desirability of the 
smart sweater. She saw in this innovation a means to increase equality between students and reduce the social costs associated with teenagers who drop out of school:

We know that dropping out of school is a scourge, which causes all sorts of consequences: low self-esteem, violence, gang phenomena, drug use. Also, from an economic standpoint, they may possibly cost more to society in terms of care, low income, hence a lesser contribution in terms of taxes (Jeanne, Workshop $1^{*}$ ).

In contrast, Éloïse claimed on the online forum that the smart sweater fostered an undesirable social norm of performance. She criticized the idea of "a smooth world, virtuous without virtues, constipated and artificially harmonious where conflicts subside on the spot, where individual capacities are pushed to their maximum" and feared that teachers or parents would be tempted to "get rid of young people by telling them to put on their 'smart' plasticized chainmail and calm the cake, even before any conflict breaks out" (Éloïse, Forum 2030). Like many other participants, Éloïse refused to envision a behaviourally homogeneous community where only one form of intelligence is acknowledged and valued.

Hence, the judgments regarding the desirability of the smart sweater of Jeanne and Éloïse differed, but they both relied on and made explicit their own beliefs regarding the social and moral values their community should seek. In other words, they bring to the fore the social and moral values they would like to see promoted from a collective perspective. As a result, this mode of engagement enables the group to challenge each other's assumptions. For instance, during a workshop discussion, many participants found the assistive robot to be undesirable on the assumption that elderly people would not be at ease with such a technological device. Malik offered nuances to such a critique:

I'd like to come back on the issue of the capability of using [the robots]. I believe it depends on the horizon time frame that it takes us to develop them. [...] I've a little boy who at two years old was on the phone and able to figure out how it works. I mean, people of this generation, when they'll approach retirement, operating robots, teaching them stuff, that'll be their day-to-day. Myself, I'm really not worried. [But if] we provide this technology tomorrow, it's clear that it won't work. All depends upon the moment we implement it and whether people in society already live in proximity with robots or other technologies (Malik, Workshop 3).

Malik's comment invited others to reflect on the innovation by considering implementation issues that went beyond the current state of things. Sarah, who was in the same workshop, picked up on his comment and introduced additional social and political considerations: 
Malik referred to his two-year-old son, but would he prefer that his little guy takes care of him when he gets old or that a robot does so? These are the questions that must be asked as human beings, as a society. Yes, [the robot] surely could help caregivers, those who have to travel [to provide home care]. But, from a legal point of view, I think it'd really create a lot of problems, for insurance or things like that, or if the robot has a bug. It's someone's life that's at stake: what happens if the robot forgets to give a medication? ... I think it opens the door to many problems (Sarah, Workshop 3).

Sarah thus both challenged and complemented Malik's argument, inviting the group to reflect upon the importance for technology developers to consider and anticipate the evolving capacities of users as well as the values underpinning home care for the elderly people.

Overall, this mode of engagement enabled participants to address the desirability of health innovations by referring to fundamental rights, social costs, privacy, individual freedom, environmental protection, responsibilities of private and public actors, etc. These arguments thus shed light on collective concerns in regard to technological advances in health.

\section{Engaging as a Potential User}

When participants engaged as potential users, they judged the fictional technologies through resources that differed from those described earlier and enabled them to react to what they saw as potential flaws in a technology. For instance, Adrian referred to his own preferences and feelings to question the integration of the smart sweater in the daily life of its users: "even if I had such a device, I wouldn't be interested to look at it when I'd be stressed. I know when I'm stressed! I think it'd get on my nerves even more to look at it!" (Adrian, Workshop 2). By sharing his personal discomfort, Adrian evoked the problem of intrusion and brought participants to think about the world people want to live in. Similarly, Walter shared on the online forum an intimate personal reflection, explaining why he did not consider the smart sweater desirable:

I'd say that family support and a positive and constant encouragement could have the same, if not a better, impact than the smart sweater. We tend to forget that we are responsible for our successes as much as our failures. We deny our responsibility, evoking factors that are unrelated to the events. We reduce our feelings of guilt for not having tried hard enough, and it's increasingly common to also see parents attributing the cause of their child's failures on other things or other people to avoid acknowledging that, in fact, they're responsible (Walter, Forum 2030).

By engaging as potential users, participants also pondered the value of various technical functionalities and their likely impact on the user. One key problem with the assistive robot was to determine what functionalities would be beneficial and to which user: 
On our telephones, we enter the numbers in the directory and we no longer practice our memory. I don't even know my daughter's phone number. I know it's programmed "6". [...] It can go even further with this kind of robot ... not only it won't improve autonomy, it will diminish it. [...] For someone who starts to do some arthritis, it's recommended to walk a little. Well, with this robot, the person will say "Good! the robot can do everything for me." I think we should decompose the functions of the robot, remove those that are superfluous, which don't support autonomy (Fabien, Workshop 1).

Although several participants considered that the robot should not to be introduced as a substitute for home-care services and human interactions, Jeanne did not hesitate to draw on her own situation to provide a counterpoint:

We raised the issue of the human, the human, the human ... But we must also think that ... that we could use it wisely [...]. Myself, I live alone and I often say to myself: "If my kids don't call me" - because they don't call me very often - I say to myself: "Shit, what will happen to me if I die right there! Anything can happen and they won't know because they don't call or they don't come" (Jeanne, Workshop 1).

Jeanne's reference to her daily life thus invited the group to consider how the robot could increase older people's safety and reduce their isolation, thereby pushing them to reflect on what caring may mean in such context. Similarly, Theresa responded to the participants of her own group who criticized the device for being dehumanizing. She mobilized her own experience as a blind person to explain why such technology should be considered valuable:

Personally, I find that quite brilliant. [... Since I'm blind myself, I know that people are often exhausted when helping us out all the time. I think it could offer a moment of rest that would be very interesting to the people around us. Otherwise, it is true that there are inconveniences. It's very nice to be with other human beings, the contact is certainly different, this bothers me a little, but for those moments where people do need respite, I think it could be marvellous (Theresa, Workshop 2).

Addressing the others as someone whose autonomy is compromised, Theresa not only explained why she, as a potential user, would appreciate the technology but also brought to the debate caregiver respite. She called the attention of other participants to an issue they might not had fully understood otherwise, bringing meaningful nuances to the deliberations.

Overall, when engaging as potential users, participants shared their thoughts about how the innovations might affect their daily life, and enabled the group to ponder social and ethical issues that may surface through a more intimate understanding of the context of use (e.g., isolation, dependence upon relatives, adverse effects of certain functionalities, sense of safety, etc.). 


\section{Discussion}

Untangling the multiple social and ethical issues arising from health innovations is a complex program (Wortley et al. 2017). It implies not only acknowledging "hard" impacts like risks for human health and safety but also looking at "soft" impacts that may affect daily routines and collective identity (Swierstra and Molder 2012). This partly explains why specific attention has been given to the relationship between HTA and democratic governance. In a deliberative democracy, the voices of non-experts need to be heard and inform policy making (Gutmann and Thompson 2009). Hence, important research efforts have been devoted in the past decades to experiment with and assess the impact of different public and user engagement mechanisms (Degeling et al. 2015; Sanders and Stappers 2008).

In this paper, our aim was to generate methodological insights on the deliberative processes themselves because the issues being emphasized by participants depend upon the perspective they adopt or are told to adopt. Notwithstanding the fact that our sample comprised more women and educated individuals, our findings showed how two contrasting modes of engagement characterized our participants' deliberations. Their ability to shift from one mode of engagement to another generated rich debates about the social and ethical issues raised by health innovations, and both modes of engagement brought to the group discussions concerns that were complementary. In particular, participants adopting a user mode offered counterpoints to the claims of participants adopting a public representative mode: personal anecdotes refocused the discussion on concrete aspects.

Although further conceptual and methodological insights into public involvement in HTA are needed (Gagnon et al. 2011; Krinks et al. 2015; Wortley et al. 2016), our findings can inform the design of deliberative mechanisms and the way group discussions are moderated. Because the two modes of engagement entail different yet mutually challenging ways of appraising health innovations, we suggest that deliberative processes be designed so as to deliberately solicit both personal and collective reflections. For instance, participants could be asked to sequentially share and ponder personal and collective concerns. To support more challenging group discussions, the moderator could also explicitly solicit arguments from one standpoint and then invite participants to think about and raise potential counterpoints from the other standpoint.

The respective limitations of these modes of engagement should also be carefully considered because public involvement is increasingly seen as a way to enhance the legitimacy of public policies (Gagnon et al. 2016; Wortley et al. 2017). While engaging as a public representative is typically considered the ideal to be pursued within a deliberative democracy framework, such a mode of engagement may contribute to the problem critics of deliberative democracy call the authenticity problem (King et al. 1998). This problem is understood as a limit induced when participants would, among other things, "lack sufficient expertise to understand, articulate, and form meaningful judgments on the relevant issues" (Degeling et al. 2015: 115). Engaging as a potential user enables participants to draw on concrete details 
and contextual elements, but it may, on the other hand, lead them to downplay key aspects of the common good (Burgess 2014; Krinks et al. 2015). For instance, as a user, one may accept short-term benefits despite the fact that long-term risks remain unknown, or one may support certain trade-offs between individual and collective concerns (Montesanti et al. 2016). Another element that may undermine the authenticity of an argument is related to the ways in which individual beliefs and commonly shared concerns are intertwined (Innes and Booher 2004). For instance, there is a thin line between one's own beliefs and the beliefs of the collective within which this person is evolving. From a deliberative standpoint, assuming that one's way of seeing the world is shared by a broader group is problematic because such claims may easily gain the approval of other participants, closing down the discussion too rapidly.

\section{Conclusion}

While public involvement is gaining traction in many public policy domains, knowing how to handle the multifaceted nature of the lay opinions that are gathered through deliberative processes is methodologically challenging. One key object of contention is deciding whether participants should be contributing on the basis of their own personal perspective or whether they should be encouraged to talk on behalf of the broader collective. Acknowledging how the two modes of engagement we described enable participants to share opinions that not only complement but also challenge those of each other is important for practitioners of public involvement. Enabling both modes of engagement to coexist in a given public involvement mechanism could help to develop a richer understanding of the social and ethical issues raised by health innovations. This would be more consistent with the deliberative democracy ideal wherein difficult decisions need to be carefully pondered by a broad and diversified set of citizens.

Correspondence may be directed to: Pascale Lehoux, Professor, Department of Health Management, Evaluation and Policy, University of Montreal, Institute of Public Health Research of University of Montreal (IRSPUM); P.O. Box 6128, Branch Centre-ville, Montreal, QC H3C 3J7; tel.: 514-343-7978; fax: 514-343-2448; e-mail: pascale.lehoux@umontreal.ca.

\section{References}

Blokker, P. and A. Brighenti. 2011. "An Interview with Laurent Thévenot: On Engagement, Critique, Commonality, and Power." European Journal of Social Theory 14(3): 383-400.

Boenink, M., T. Swierstra and D. Stemerding. 2010. "Anticipating the Interaction between Technology and Morality: A Scenario Study of Experimenting with Humans in Bionanotechnology." Studies in Ethics, Law, and Technology 4(2): 1-38.

Bombard, Y., J. Abelson, D. Simeonov and F.P. Gauvin. 2011. "Eliciting Ethical and Social Values in Health Fechnology Assessment: A Participatory Approach." Social Science and Medicine 73(1): 135-44.

Burgess, M.M. 2014. "From 'Trust Us' to Participatory Governance: Deliberative Publics and Science Policy." Public Understanding of Science 23(1): 48-52. 
Charles, J. 2012. "Comment la cartographie méconnaît les habitants." Participations 4(3): 155-78.

Degeling, C., S.M. Carter and L. Rychetnik. 2015. "Which Public and Why Deliberate? - A Scoping Review of Public Deliberation in Public Health and Health Policy Research." Social Science and Medicine 13(1): 114-21.

Delgado, A., K.L. Kjølberg and F. Wickson. 2010. "Public Engagement Coming of Age: From Theory to Practice in STS Encounters with Nanotechnology." Public Understanding of Science 20(6): 1-20.

Facey, K., A. Boivin, J. Gracia, H.P. Hansen, A. Lo Scalzo, J. Mossman et al. 2010. “Patients' Perspectives in Health Technology Assessment: A Route to Robust Evidence and Fair Deliberation." International Journal of Technology Assessment in Health Care 26(03): 334-40.

Gagnon, M.P., B. Candas, M. Desmartis, M. Rhainds, M. Coulombe, J. Gagnon et al. 2016. “Engaging Patient Representatives in the Identification and Prioritization of Health Technology Assessment Topics." International Journal of Hospital-Based Health Technology Assessment 1: 31-40.

Gagnon, M.P., M. Desmartis, D. Lepage-Savary, J. Gagnon, M. St-Pierre, M. Rhainds et al. 2011. “Introducing Patients' and the Public's Perspectives to Health Technology Assessment: A Systematic Review of International Experiences." International Journal of Technology Assessment in Health Care 27(01): 31-42.

Gutmann, A. and D. Thompson. 2009. Why Deliberative Democracy? Princeton, NJ: Princeton University Press.

Hansen, E.C. 2006. Successful Qualitative Health Research: A Practical Introduction. Crows Nest, NSW: Allen and Unwin.

Innes, J.E. and D.E. Booher. 2004. "Reframing Public Participation: Strategies for the 21st Century." Planning Theory and Practice 5(4): 419-436.

King, C.S., K.M. Feltey and S. Bon. 1998. “The Question of Participation: Toward Authentic Public Participation in Public Administration." Public Administration Review 58(4): 317-26.

Krinks, R., E. Kendall, J.A. Whitty and P.A. Scuffham. 2015. “Do Consumer Voices in Healthcare Citizens' Juries Matter?" Health Expectations 19: 1015-22.

Lehoux, P., P. Gauthier, B. Williams-Jones, F.A. Miller, J.J. Fishman, H. Hivon et al. 2014. “Examining the Ethical and Social Issues of Health Technology Design Through the Public Appraisal of Prospective Scenarios: A Study Protocol Describing a Multimedia-Based Deliberative Method." Implementation Science 9(1): 81.

Montesanti, S.R., J. Abelson, J.N. Lavis and J.R. Dunn. 2016. “Enabling the Participation of Marginalized Populations: Case Studies from a Health Service Organization in Ontario, Canada." Health Promotion International 32(4): 636-49.

Richard-Ferroudji, A. 2012. «Limites du modèle délibératif : composer avec différents formats de participation. » Politix 96(4): 161-81.

Sanders, E.B.N. and P.J. Stappers. 2008, "Co-Creation and the New Landscapes of Design." Co-design 4(1): 5-18.

Swierstra, T. and H. Molder. 2012. "Risk and Soft Impacts." In S. Roeser, R. Hillerbrand, P. Sandin and M. Peterson, eds., Handbook of Risk Theory. The Netherlands: Springer.

Thévenot, L. 2007. "The Plurality of Cognitive Formats and Engagements Moving Between the Familiar and the Public." European Journal of Social Theory 10(3): 409-23.

Wortley, S., J. Street, W. Lipworth and K. Howard. 2016. “What Factors Determine the Choice of Public Engagement Undertaken by Health Technology Assessment Decision-Making Organizations?" Journal of Health Organization and Management 30(6): 872-90.

Wortley, S., A. Tong and K. Howard. 2017. "Community Views and Perspectives on Public Engagement in Health Technology Assessment Decision-Making." Australian Health Review 41: 68-74.

Young, I.M. 1996. "Communication and the Other: Beyond Deliberative Democracy." In S. Benhabib ed. Democracy and Difference: Contesting the Boundaries of the Political. Princeton, NJ: Princeton University Press. Young, I.M. 2001. "Activist Challenges to Deliberative Democracy." Political Theory 29(5): 670-90. 